\title{
Anatomical considerations for the development of a new transcatheter aortopulmonary shunt device in patients with severe pulmonary arterial hypertension
}

\author{
Kenneth Guo,' David Langleben, ${ }^{2}$ Jonathan Afilalo, ${ }^{3}$ Avi Shimony, ${ }^{3}$ Richard Leask, ${ }^{4}$ \\ Ariane Marelli, ${ }^{1}$ Giuseppe Martucci, ${ }^{1}$ Judith Therrien ${ }^{1,3}$ \\ 'McGill Adult Unit for Congenital Heart Disease Excellence, Royal Victoria Hospital, Montreal, Quebec, Canada; \\ ${ }^{2}$ Center for Pulmonary Vascular Disease, Jewish General Hospital, Montreal, Quebec, Canada; ${ }^{3}$ Division of Cardiology, \\ Jewish General Hospital, Montreal, Quebec, Canada; ${ }^{4}$ Department of Chemical Engineering, McGill University, Montreal, \\ Quebec, Canada
}

\begin{abstract}
Morbidity from pulmonary arterial hypertension (PAH) ensues when the pulmonary pressure reaches suprasystemic levels. A transcatheter alternative to the Potts shunt would allow decompression of the right heart without the surgical risks. To aid development of a transcatheter aortopulmonary shunt (TAPS) device, we described the anatomic relationship between the left pulmonary artery (LPA) and the descending aorta $(\mathrm{dAO})$ in adults with severe pulmonary hypertension. Adults with severe PAH (peak systolic pulmonary arterial pressure $[\mathrm{PASP}] \geq 80 \mathrm{mmHg}$ ) who had computed tomography of the chest were enrolled. Measurements were taken on the axial plane at the level of the pulmonary artery bifurcation. Forty patients (male sex, 9 patients; median age \pm standard deviation [SD], $59 \pm 15$ years; median PASP $\pm \mathrm{SD}, 93 \pm 12 \mathrm{mmHg}$ ) were identified. The mean distance $( \pm \mathrm{SD})$ between the LPA and $\mathrm{dAO}$ was $2.3 \pm 3.1 \mathrm{~mm}$. The mean luminal $\mathrm{dAO}$ and LPA diameters $( \pm \mathrm{SD})$ were $23.4 \pm 3.8 \mathrm{~mm}$ and $25.5 \pm 5.1 \mathrm{~mm}$, respectively. The LPA and dAO approximated in $93 \%$ of patients, with $38 \%$ having aortic calcification at the contact site. The mean "landing zone" width and height (defining an area with distance $<4 \mathrm{~mm}$ between the outer borders) of the two arteries were $15.7 \pm 3.4 \mathrm{~mm}$ and $20.6 \pm 4.3 \mathrm{~mm}$, respectively, at a mean distance of $28.0 \pm 7.6 \mathrm{~mm}$ from the main pulmonary artery bifurcation. This study shows that the landing zone is able to accommodate a TAPS device of up to $15 \mathrm{~mm}$ in diameter in the majority of patients with severe PAH.
\end{abstract}

Keywords: aorta, pulmonary angiography, imaging (CT).

Pulm Circ 2013;3(3):639-646. DOI: 10.1086/674328.

Address correspondence to Judith Therrier, McGill Adult Unit for Congenital Heart Disease Excellence, Royal Victoria Hospital, 687 Pine Avenue West, Montreal, Quebec H3A 1A1, Canada. E-mail: judith.therrien@mcgill.ca.

Submitted January 2013; Accepted March 2013; Electronically published November 18, 2013.

(C) 2013 by the Pulmonary Vascular Research Institute. All rights reserved. 2045-8932/2013/0303-0017. \$15.00. 


\section{INTRODUCTION}

Pulmonary arterial hypertension (PAH) is a group of heterogeneous conditions that share comparable clinical and hemodynamic features and almost identical changes in the lung microcirculation. ${ }^{1,2}$ The poor prognosis associated with PAH is principally related to the sustained eect of pressure loading of the right ventricle, with ensuing right ventricular failure and early death, particularly when the pulmonary pressure reaches suprasystemic levels. ${ }^{2-5}$

Conversely, despite similar morbidity, survival in patients with Eisenmenger syndrome is clearly better than in those with idiopathic PAH. Although the exact mechanisms of this survival advantage over patients with idiopathic PAH are unclear, it seems likely that the integrity of right ventricular function, rather than the degree of vascular injury, is a major determinant of symptoms and survival in PAH. ${ }^{5}$ One theory is that the right ventricular afterload in patients with Eisenmenger syndrome never reaches suprasystemic levels because it can be partly relieved through a defect that permits right-to-left shunting. This leads to decompression of the right heart chambers, an increase in left ventricular preload, and hence systemic cardiac output, albeit at the expense of increasing cyanosis.

This reasoning formed the basis for graded balloon atrial septostomy, a treatment option for patients with PAH who are functional class IV with right heart failure refractory to medical therapy. 2,6,7 However, this procedure is associated with a worldwide mortality of $16 \%$, and patients with a mean right atrial pressure $>20 \mathrm{mmHg}$ or those with severe right heart failure fare worse. ${ }^{2,7,8}$ In these patients, atrial septostomy can cause massive and sudden right-to-left shunting and central cyanosis, and it may result in insucient pulmonary blood flow and severe refractory hypoxemia, which is the most common reason for early mortality. ${ }^{7,8}$

By contrast, a surgical anastomosis between the left pulmonary artery (LPA) and the descending thoracic aorta (dAO), which is known as a Potts shunt, in patients with $\mathrm{PAH}$ has some distinct theoretical advantages in that it can result in an immediate decrease in the right ventricular afterload while sparing the brain and myocardium from cyanotic blood and paradoxic emboli, as opposed to an anastomo- sis at the level of the ascending aorta and right pulmonary artery. Although this surgical procedure has been performed in a small number of pediatric cases, the chief concern remains the perioperative risk in adult patients with severe pulmonary hypertension. ${ }^{7,8}$

Because of the high perioperative mortality and the problems with dissecting multiple bronchial collaterals in the lung hilum, a transcatheter alternative to the surgical creation of a Potts shunt would be an attractive option.' The essential initial step is to understand the anatomic relationships and dimensions of the dAO and the LPA in patients with severe pulmonary hypertension. This would help determine the feasibility of a transcatheter aortopulmonary shunt (TAPS) and would also help guide device design, method of approach, and delivery. To achieve this, we evaluated the LPA and the dAO in patients who had computed tomography (CT) of the chest.

\section{MATERIAL AND METHODS}

\section{Study population}

Our study population comprised patients attending the Centre for Pulmonary Vascular disease at the Jewish General Hospital, Montreal, Quebec, Canada, for investigations of pulmonary hypertension. All patients included in our study had a final diagnosis of World Health Organization (WHO) class I PAH, whereas those with WHO classes 2-5 (nonPAH) were excluded. In addition, we excluded patients with a peak pulmonary artery systolic pressure $<80 \mathrm{mmHg}$, because these individuals bear less resemblance to the final target population. According to routine protocols in our center, high-resolution non-contrast-enhanced CTs are obtained during the diagnostic work-up of patients. We included only those patients who had additional contrast-enhanced CT obtained to rule out aortic dissection, pulmonary emboli, or lung cancer. The local institutional review board approved the study.

\section{CT measurements}

To better understand how to design and deliver a device that would replicate the physiology of a surgical Potts shunt, we considered the following 3 key areas in the CT analysis: 
1. Feasibility. The surgical creation of a Potts shunt involves a left thorocotomy, allowing the surgeon to physically approximate and surgically anastamose the LPA and dAO. Because this is not possible from a transcatheter approach, the spatial relationship and separation between the LPA and DAO needed to be evaluated (Figs. 1, 2). The distance between the LPA and dAO where they approximate the closest in axial CT sections was thus measured. The patients were divided into type I, with the distance between the outer borders of the great vessels $\leq 4 \mathrm{~mm}$, and type II, with the distance $>4 \mathrm{~mm}$.

2. Transarterial puncture and device delivery. To deliver the device, one will need to puncture from the dAO into the LPA and then introduce the delivery catheter via the dAO. To further define and risk stratify that approach and to facilitate design of the delivery system, LPA and dAO measurements were taken at the level of closest approximation of both arteries (usually at the level of the PA bifurcation) and included LPA and $\mathrm{dAO}$ maximal luminal diameters, the distance from the main pulmonary artery bifurcation to the midpoint of the LPA-dAO contact point, and presence of LPA and dAO calcification at the contact point of the two great vessels (Fig. 2).

3. Device size. To facilitate design of a device that permits adequate right-to-left shunting to eect both a hemodynamic and symptomatic benefit, the width and height of the contact point between the LPA and dAO when their outer borders approximated by $\leq 4 \mathrm{~mm}$, without any intervening lung tissue, were measured. The landing zone for TAPS deployment comprised (1) landing zone width (defined in the axial plane) and (2) landing zone height (which we defined in the sagittal and coronal plane; Figs. 1-3).

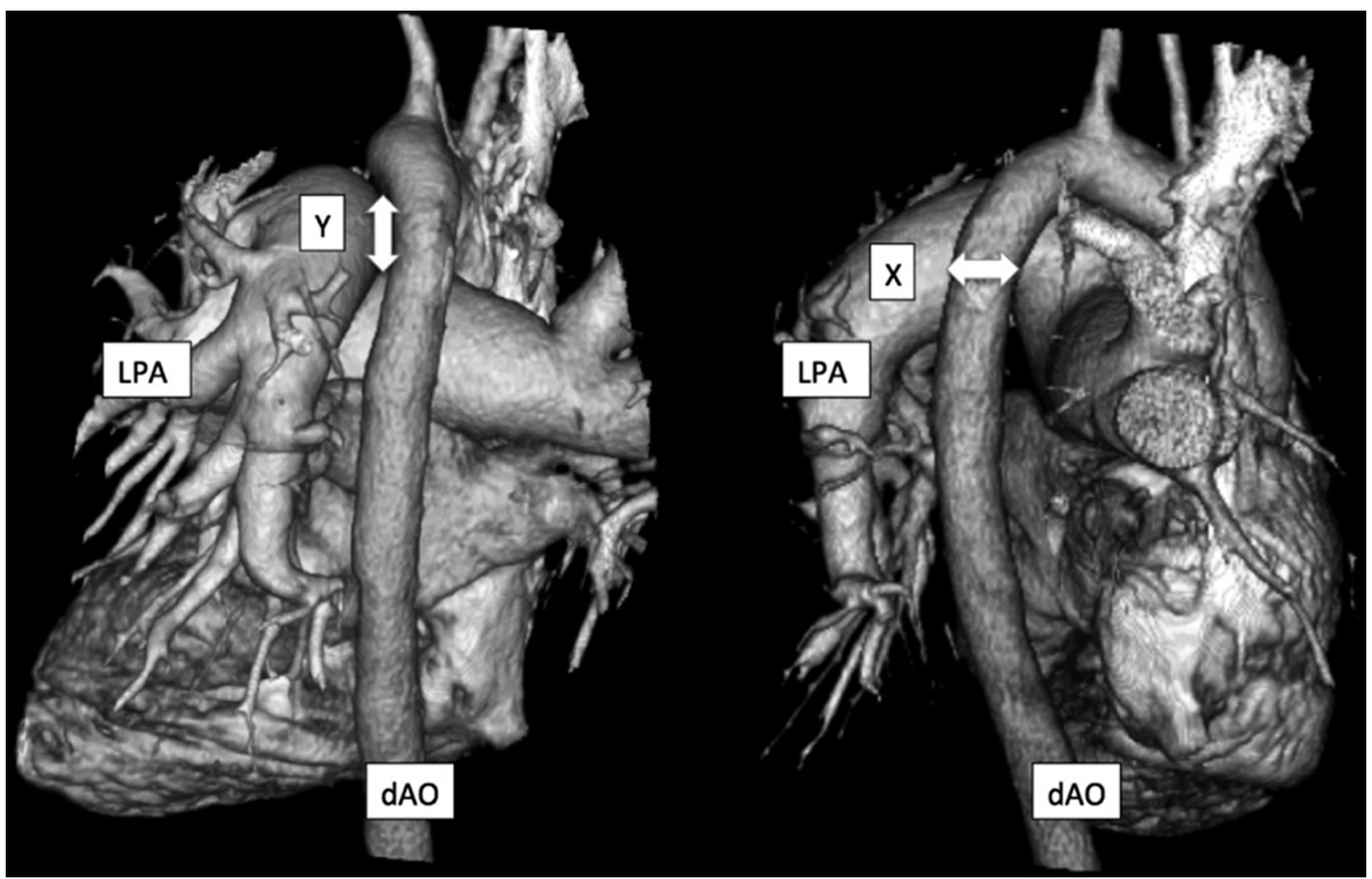

Figure 1. Three-dimensional volumetric reconstruction of the descending aorta (dAO) and left pulmonary artery (LPA). Note the spatial relationship of the LPA and dAO. Left, vertical arrow and letter "Y" denote landing zone height. Right, horizontal arrow and letter "X" denote landing zone width. A color version of this figure is available in the online edition. 


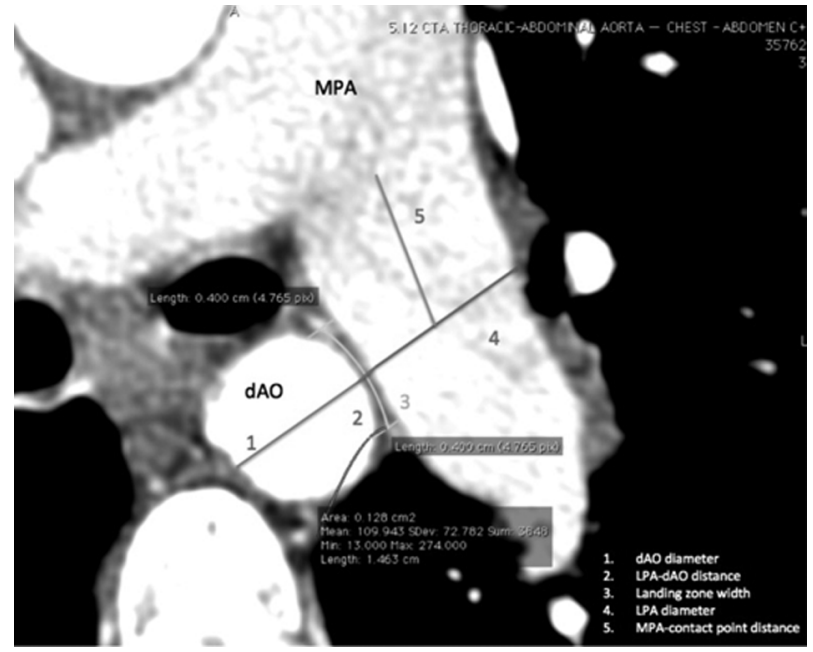

Figure 2. Type I relationship of the left pulmonary artery (LPA) and descending aorta $(\mathrm{dAO})$. Measurements taken in this view: (1) maximum dAO diameter; (2) distance between LPA and dAO; (3) landing zone width; (4) LPA diameter; (5) distance between main pulmonary artery (MPA) and contact point of the great arteries. A color version of this figure is available in the online edition.

The dimensions were crosschecked through a second method of measurement and subsequently verified by a second independent observer.

\section{Statistical analysis}

All data were analyzed using SPSS, version 16 . Between-group comparisons of baseline variables were performed using a $t$ test for continuous variables and Fisher exact test for categorical variables, with $P<0.05$ taken as significant.

\section{RESULTS}

There were 40 patients with PAH and a systolic pulmonary arterial pressure of $\geq 80 \mathrm{mmHg}$ who had a high-resolution CT of the chest obtained. Sixteen of these patients underwent contrast-enhanced CT. There were no statistical dierences in the baseline characteristics and CT dimensions between the patients who had contrast-enhanced and non-contrast-enhanced CT obtained (Table 1). The study population was predominantly female (31 [77.5\%] of 40$)$, with a median $\left({ }^{ \pm} \mathrm{SD}\right)$ age of $59 \pm 15$ years and a peak systolic pulmonary artery pressure of $93 \pm 12 \mathrm{mmHg}$. The characteristics of the study population are summarized in Table 1.

Interobserver variability and $95 \%$ confidence intervals were as follows: for dAO diameter, $0.03 \mathrm{~mm}$ $(-0.23$ to 0.28$)$; for LPA diameter, $0.02 \mathrm{~mm}(-0.57$ to 0.60$)$; for landing zone width, $0.02 \mathrm{~mm}(-0.32$ to $0.27)$; for landing zone height, $0.05 \mathrm{~mm}(-0.29$ to 0.38); for minimal distance between $\mathrm{dAO}$ and LPA, $0.01 \mathrm{~mm}(-0.07$ to 0.05$)$; and for distance between main pulmonary artery bifurcation to center of landing zone, $0.03 \mathrm{~mm}$ ( -0.53 to 0.47$)$.

\section{Feasiblity}

The mean distance between the LPA and dAO was $2.3 \pm 3.1 \mathrm{~mm}$. Thirty-seven patients $(93 \%)$ had an

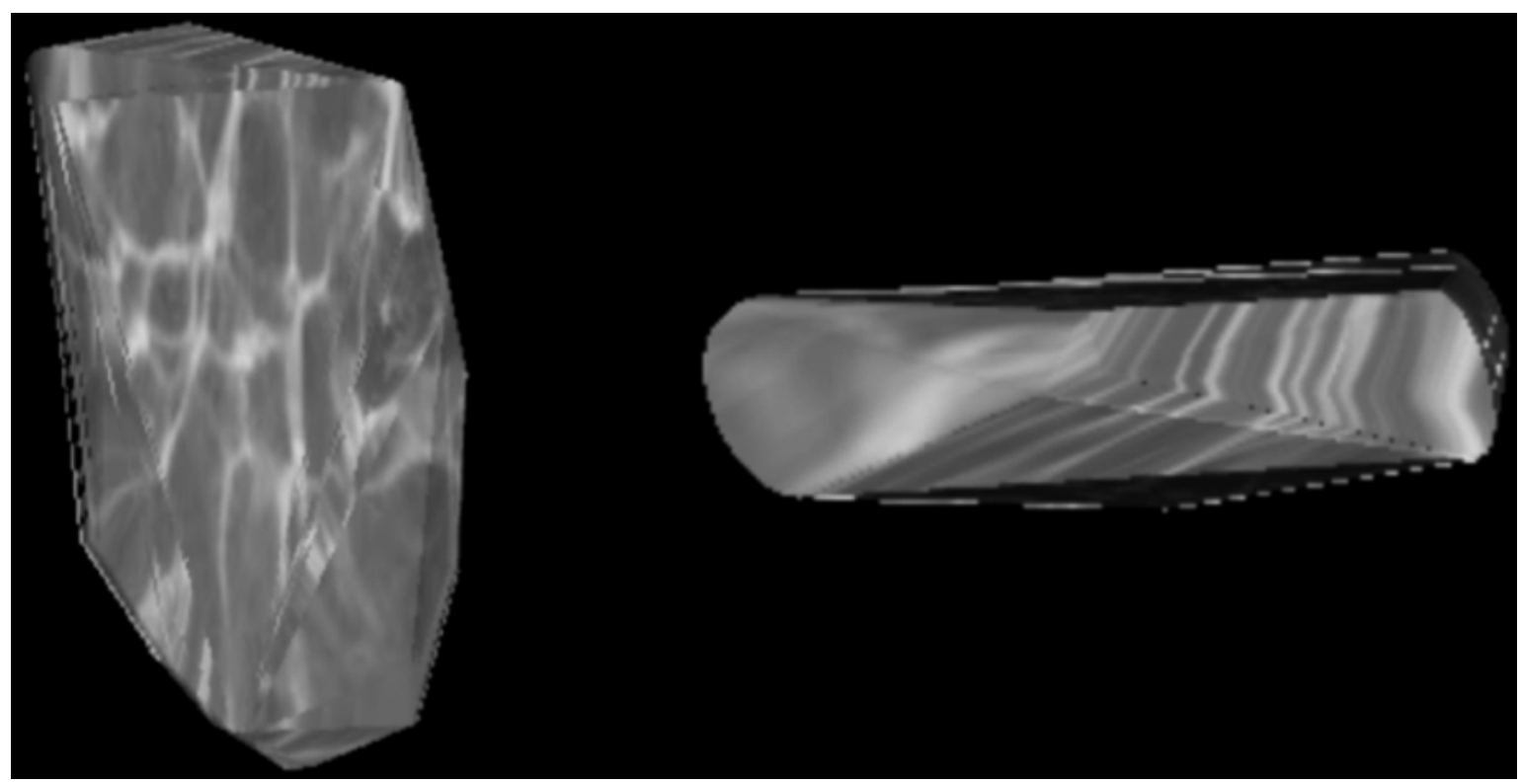

Figure 3. Three-dimensional reconstruction of an example of a landing zone. A color version of this figure is available in the online edition. 
Table 1. Baseline characteristics of the study population

\begin{tabular}{|c|c|c|c|c|}
\hline Variable & Whole $(n=40)$ & $\begin{array}{l}\text { Contrast-enhanced } \\
\text { CT }(n=16)\end{array}$ & $\begin{array}{c}\text { Non-contrast-enhanced } \\
\text { CT }(n=24)\end{array}$ & $P$ \\
\hline Mean age $\pm S D$, years & $59.2 \pm 15$ & $61.2 \pm 12$ & $57.9 \pm 17$ & 0.5059 \\
\hline Female sex & $31(78)$ & $14(88)$ & $17(71)$ & 0.2717 \\
\hline \multicolumn{5}{|l|}{ Mean peak systolic pulmonary } \\
\hline $\mathrm{DM}$ & $10(25)$ & $7(44)$ & $3(13)$ & 0.0588 \\
\hline Hpt & $15(38)$ & $8(50)$ & $7(29)$ & 0.2046 \\
\hline Dyslipidaemia & $9(23)$ & $3(19)$ & $6(25)$ & 0.7171 \\
\hline Smoker & $14(35)$ & $5(31)$ & $9(38)$ & 0.7462 \\
\hline \multicolumn{5}{|l|}{$\begin{array}{c}\text { Mean CT measurement } \pm \\
\text { SD (range), mm }\end{array}$} \\
\hline LPA diameter & $25.5 \pm 5.1(12-40)$ & $24.3 \pm 6.0(12-32.8)$ & $26.3 \pm 4.3(20-40)$ & 0.2264 \\
\hline $\mathrm{dAO}$ diameter & $23.4 \pm 3.8(16-34)$ & $22.4 \pm 3.1(16-28)$ & $24.1 \pm 4.1(18-34)$ & 0.1669 \\
\hline Landing zone width & $15.7 \pm 3.4(8-25)$ & $16.4 \pm 3.0(12-22)$ & $15.3 \pm 3.6(8-25)$ & 0.3191 \\
\hline Landing zone height & $20.6 \pm 4.3(14-31)$ & $19.1 \pm 3.7(14-26)$ & $21.7 \pm 4.4(14-31)$ & 0.0590 \\
\hline $\begin{array}{l}\text { Distance between LPA } \\
\text { and dAO }\end{array}$ & $2.3 \pm 3.1(0.9-17)$ & $2.6 \pm 3.8(0.1-17)$ & $2.0 \pm 2.6(0.9-13.7)$ & 0.5560 \\
\hline MPA contact point distance & $28.0 \pm 7.6(15-50)$ & $28.7 \pm 6.4(19-39)$ & $27.6 \pm 8.3(15-50)$ & 0.6567 \\
\hline \multicolumn{5}{|l|}{ CT characteristic } \\
\hline LPA & & & & 1.000 \\
\hline Type I & $37(93)$ & $15(94)$ & $22(92)$ & \\
\hline Type II & $3(7)$ & $1(6)$ & $2(8)$ & \\
\hline $\mathrm{dAO}$ calcification at contact point & $14 / 37(38)$ & $4 / 15(27)$ & $10 / 22(45)$ & 0.3136 \\
\hline $\begin{array}{l}\text { Pulmonary artery calcification } \\
\text { at contact point }\end{array}$ & $2 / 37(5)$ & $1 / 15$ (7) & $1 / 22(5)$ & 1.000 \\
\hline
\end{tabular}

Note: Data are no. (\%) of patients, unless otherwise indicated. CT, computed tomography; dAO, descending aorta; DM, diabetes mellitus; Hpt, hypertension; LPA, left pulmonary artery; MPA, main pulmonary artery; SD, standard deviation.

LPA-dAO distance $<4 \mathrm{~mm}$ (type I), and 3 patients (7\%) had an LPA-dAO distance $>4 \mathrm{~mm}$ (type II; Figs. 4, 5).

\section{Transarterial puncture and device delivery}

The mean maximal dAO diameter was $23.4 \pm 3.8 \mathrm{~mm}$, and the mean maximal LPA diameter was $25.5 \pm 5.1$ $\mathrm{mm}$ with the LPA contact point being $28.0 \pm 7.6 \mathrm{~mm}$ from the main pulmonary artery. In total, 14 (38\%) of 37 patients had calcification of the descending aorta at the landing zone.

\section{Device size as determined by the landing zone}

In those patients with a type I relationship (distance, $<4 \mathrm{~mm}$ ), the mean landing width and height of the two arteries were $15.7 \pm 3.4 \mathrm{~mm}$ and $20.6 \pm 4.3 \mathrm{~mm}$, respectively.

\section{DISCUSSION}

In advanced idiopathic $\mathrm{PAH}$, either normal right ventricle function or compensated hypertrophy is critical for survival. ${ }^{5}$ Advances in specific medical therapy, particularly with respect to selective endothelin anatagonists, phosphodiesterase type 5 inhibitors, and prostanoids, either alone or in combination with other therapies, have been shown to modestly improve exercise capacity, functional class, hemodynamics, echocardiographic variables, and time to clinical worsening., ${ }^{2,10}$ However, despite these medical advances, PAH still confers a dismal prognosis, 


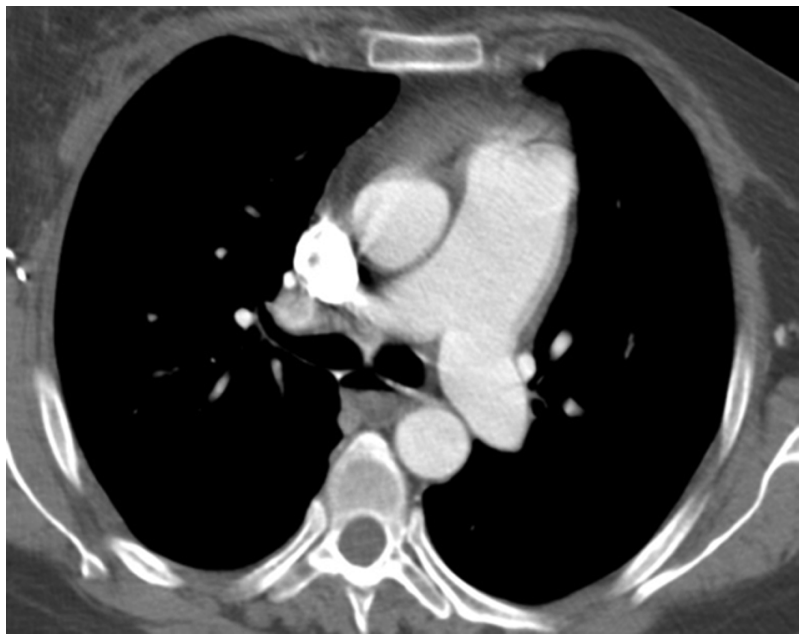

Figure 4. Type I relationship of the left pulmonary artery and descending aorta in this axial computed tomography slice at the pulmonary artery bifurcation. The distance between the two arteries measured $1.4 \mathrm{~mm}$. A color version of this figure is available in the online edition.

with many patients progressing relentlessly to WHO functional class IV and right heart failure before a transplant option becomes feasible. ${ }^{2}$ Because of the survival benefit seen in patients with Eisenmenger syndrome or in patients with $\mathrm{PAH}$ with a patent foramen ovale, the concept of decompressing the right ventricle in PAH to prolong survival is well accepted. ${ }^{7}$ The creation of a right-to-left shunt (usually by graded balloon or blade atrial septostomy) decompresses the right heart, increases left cardiac output, and, despite a decrease in systemic arterial oxygen saturation, augments systemic oxygen transport. ${ }^{6,7}$ Evidence suggests benefit from this intervention in patients who are in WHO functional class IV with right heart failure refractory to medical therapy or who have syncope. Despite this, mortality associated with conventional atrial septostomy is high, and early mortality is mainly due to excess right-to-left shunting, poor pulmonary flow, and refractory hypoxemia. ${ }^{6}$ To avoid sudden central nervous system exposure to refractory hypoxemia encountered in atrial septostomy, as an alternative, a surgical Potts anastamosis (an anastamosis between the LPA and dAO, distal to the head and neck blood vessels) has been reported in 8 children with suprasystemic pulmonary hypertension of varying etiology experiencing failure of drug therapy. In this series, there were 2 postoperative deaths (mortality, 25\%). The 6 surviving patients remained alive at a mean $( \pm \mathrm{SD})$ of $63.7 \pm 16.1$ months of follow-up with significant improvement of 6-minute-walk distance and a decrease in brain natriuretic peptide. ${ }^{15}$

Because of the relatively high surgical risk for patient with advanced $\mathrm{PAH}$, we were interested in exploring the possibility of creating a TAPS analogous to the surgically created Potts shunt that would recreate the same beneficial physiology with dierential blood flow but would avoid general anesthesia and a left thoracotomy. To consider this procedure via a transcatheter approach, it was necessary to fully understand the anatomy of the LPA and dAO and their spatial relationship to one another in patients with $\mathrm{PAH}$.

Feasibility. First, we were able to show that a transcatheter shunt would be feasible in $93 \%$ of our patients because of a separation distance of $<4 \mathrm{~mm}$ between the LPA and dAO. However, in 7\% of patients with PAH, the LPA and dAO did not approximate (a type II relationship; Table 1; Figure 5). In this significant percentage of patients, it seems likely that the distance between the two arteries would prohibit a transcatheter approach, because the risk of bleeding, lack of approximation of the two arteries with the device, and leak around the device would be high. To our knowledge, this is the first time that this relationship has been described and highlights the importance of careful evaluation of the anatomy before considering a patient for this technique.

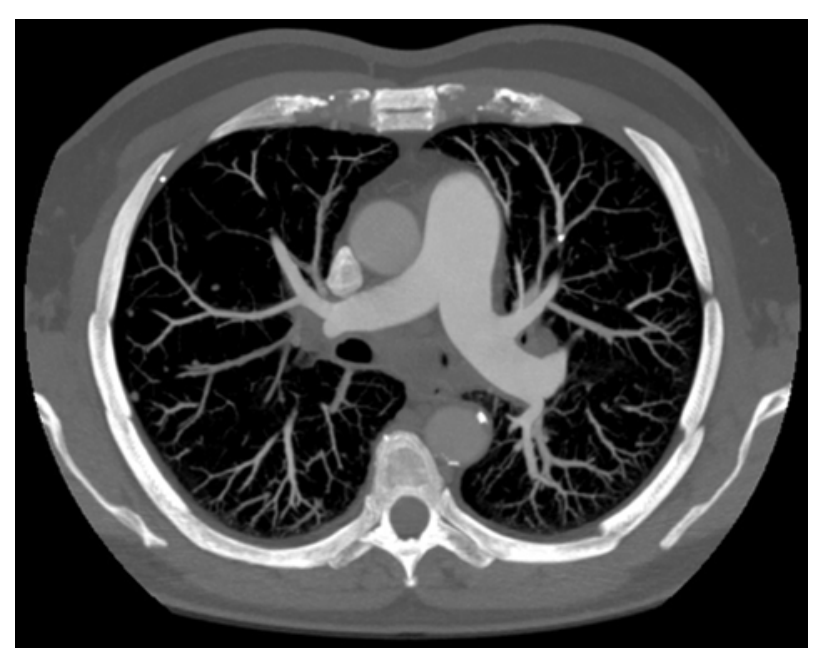

Figure 5. Type II relationship between the left pulmonary artery and descending aorta. The distance between the 2 great arteries measured $17 \mathrm{~mm}$. This arrangement is likely less suitable for transcatheter shunt creation. Note the presence of aortic calcification. A color version of this figure is available in the online edition. 
Transarterial puncture and device delivery. In those patients with close approximation of the LPA and $\mathrm{dAO}, 14(38 \%)$ of $37 \mathrm{had}$ aortic calcification at the site of contact. The presence of this aortic calcification at the contact point may in part be related to an injury response of the descending aorta to the contact point of the hypertensive pulmonary artery and will have important implications in any attempted puncture of the aorta to gain access to the LPA. The mean maximal dAO diameter was $23.4 \pm 3.8 \mathrm{~mm}$, and the mean maximal LPA diameter was $25.5 \pm 5.1 \mathrm{~mm}$ with the LPA contact point being $28.0 \pm 7.6 \mathrm{~mm}$ from the bifurcation of the main pulmonary artery. To gain access to the LPA, the approach would likely include puncturing from the dAO to the LPA. This would involve precise maneuvering in the $\mathrm{dAO}$ and LPA, with design of specific delivery catheters to maneuver in this space. The anatomical data presented in this study will allow for development of catheters and will enable the design of virtual models of the LPA and dAO to test the maneuverability and deliverability of the device. The use of angiography in a biplane catheterization laboratory with the injection of contrast into the vessel wall or the use of magnettipped catheters in both of the great arteries could help the interventionist to identify the landing zone where the great arteries approximate the closest.

Device size and design. In those patients with a type I or II relationship, we were able to evaluate the landing zone for our device with a mean $\left({ }_{ \pm} \mathrm{SD}\right)$ landing width and height of $15.7 \pm 3.4 \mathrm{~mm}$ and $20.6 \pm 4.3 \mathrm{~mm}$, respectively. This provides important information for designing a device, ensuring that it is large enough to create an appropriate-sized shunt but that it sits neatly in the landing zone and does not ultimately lead to device erosion. Although the optimal shunt size has yet to be determined, a pressure-restrictive shunt can be initially deployed to minimize uncontrolled hypoxemia. If it was considered too small, postdilatation can be done to increase the diameter if the landing zone permits. A recent case series by Esch et al. ${ }^{16}$ described the percutaneous placement of covered stents from the $\mathrm{dAO}$ to the LPA in 4 patients with PAH. One patient died periprocedurally from uncontrolled hemothorax as a result of the dynamic change in the approximation distance between the great arteries following mediastinal bleeding. The leak into the mediastinum occurred after the inadvertent removal of a sheath traversing across the created track. It can also occur after the rupture of a traversing dilating balloon. This study highlights that the possibility of a mediastinal bleed should be given due consideration for the appropriate sizing of the device length to accommodate these dynamic changes. Considerations for the device should include the type of materials used. A study by Sabi et al. ${ }^{17}$ described the use of bare metal and polytetrafluoroethylene-covered coronary stents in the surgical creation of aortopulmonary shunts in piglets. Although technically successful in 6 of 10 piglets, reevaluation 4-5 weeks later found substantial tissue ingrowth in the bare metal stents and thrombus formation in the covered stents. In addition, the design should allow for stability to prevent device migration and good radial strength, given the pulsatile nature and muscularity of both the aorta and the pulmonary arteries.

\section{Study Limitations}

This study involves only a small number of patients with severe PAH who underwent additional contrastenhanced CT of the chest. However, we do not think that this poses a problem for our results, because the measurements in non-contrast-enhanced and contrastenhanced CT were similar. Second, gated CT assessment of these patients for the engineering of the device may be important to fully understand the systolic and diastolic excursion of both arteries during the cardiac and respiratory cycles, so that an appropriate device length can be chosen to accommodate these dynamic changes while, on the other hand, avoiding excessive intraluminal device projection. We unfortunately do not have those data, because it is not a commonly performed test in the evaluation of pulmonary hypertension. However, it has been shown that the vertical and anteroposterior movement of the aorta and pulmonary artery is small and is further attenuated in patients with PAH. ${ }^{18,19}$

\section{CONCLUSION}

This study shows that the LPA and dAO have a close and describable relationship in patients with PAH. Information obtained in this study regarding the landing zone area, left pulmonary artery and 
descending aorta diameters, and distance from the main pulmonary artery bifurcation to the left pulmonary artery at the contact point are essential toward development of a TAPS device and its delivery system.

\section{REFERENCES}

1. Pietra GG, Capron F, Stewart S, Leone O, Humbert M, Robbins IM, Reid LM, Tuder RM. Pathologic assessment of vasculopathies in pulmonary hypertension. J Am Coll Cardiol 2004;43:25S-32S.

2. Galie N, Hoeper MM, Humbert M, Torbicki A, Vachiery JL, Barbera JA, Beghetti M, et al. Guidelines for the diagnosis and treatment of pulmonary hypertension: the task force for the diagnosis and treatment of pulmonary hypertension of the European Society of Cardiology and the European Respiratory Society, endorsed by the International Society of Heart and Lung Transplantation. Eur Heart J 2009;30:24932537.

3. D’Alonzo GE, Barst RJ, Ayres SM, Bergofsky EH, Brundage $\mathrm{BH}$, Detre KM, Fishman AP, Goldring RM, Groves BM, Kernis JT. Survival in patients with primary pulmonary hypertension: results from a national prospective registry. Ann Intern Med 1991;115:343-349.

4. Hopkins WE, Ochoa LL, Richardson GW, Trulock EP. Comparison of the hemodynamics and survival of adults with severe primary pulmonary hypertension or Eisenmenger syndrome. J Heart Lung Transplant 1996;15:100-105.

5. Diller G-P, Dimopoulos K, Kafka H, Ho SY, Gatzoulis MA. Model of chronic adaptation: right ventricular function in Eisenmenger syndrome. Eur Heart J Suppl 2007;9:H54-H60.

6. Klepetko W, Mayer E, Sandoval J, Trulock EP, Vachiery JL, Dartevelle P, Pepke-Zaba J, Jamieson SW, Lang I, Corris P. Interventional and surgical modalities of treatment for pulmonary arterial hypertension. J Am Coll Cardiol 2004;43: 73S-80S.

7. Keogh AM, Mayer E, Benza RL, Corris P, Dartevelle PG, Frost AE, Kim NH, Lang IM, Pepke-Zaba J, Sandoval J. Interventional and surgical modalities of treatment in pulmonary hypertension. J Am Coll Cardiol 2009;54:S67-S77.

8. Blanc J, Vouhe P, Bonnet D. Potts shunt in patients with pulmonary hypertension. New Engl J Med 2004;350:623.

9. Lansing AM. A simplified technique for performing the Waterston shunt. Ann Thorac Surg 1971;11:385-387.
10. McLaughlin VV, Oudiz RJ, Frost A, Tapson VF, Murali S, Channick RN, Badesch DB, Barst RJ, Hsu HH, Rubin LJ. Randomized study of adding inhaled iloprost to existing bosentan in pulmonary arterial hypertension. Am J Resp Crit Care Med 2006;174:1257-1263.

11. Rubin LJ, Badesch DB, Barst RJ, Galie N, Black CM, Keogh A, Pulido T, et al. Bosentan therapy for pulmonary arterial hypertension. New Engl J Med 2002;346:896-903.

12. Humbert M, Barst RJ, Robbins IM, Channick RN, Galie N, Boonstra A, Rubin LJ, Horn EM, Manes A, Simonneau G. Combination of bosentan with epoprostenol in pulmonary arterial hypertension: breathe-2. Eur Respir J 2004;24:353-359.

13. Galie N, Rubin L, Hoeper M, Jansa P, Al-Hiti H, Meyer G, Chiossi E, Kusic-Pajic A, Simonneau G. Treatment of patients with mildly symptomatic pulmonary arterial hypertension with bosentan (early study): a double-blind, randomised controlled trial. Lancet 2008;371:2093-2100.

14. Galie N, Ghofrani HA, Torbicki A, Barst RJ, Rubin LJ, Badesch D, Fleming T, et al. Sildenafil citrate therapy for pulmonary arterial hypertension. New Engl J Med 2005;353: 2148-2157.

15. Baruteau AE, Serraf A, Levy M, Petit J, Bonnet D, Jais X, Vouhe P, Simonneau G, Belli E, Humbert M. Potts shunt in children with idiopathic pulmonary arterial hypertension: long-term results. Ann Thorac Surg 2012;94:817-824.

16. Esch JJ, Shah PB, Cockrill BA, Farber HW, Landzberg MJ, Mehra MR, Mullen MP, et al. Transcatheter Potts shunt creation in patients with severe pulmonary arterial hypertension: initial clinical experience. J Heart Lung Transplant 2013;32:381-387.

17. Sabi TM, Schmitt B, Sigler M, Zanjani KS, Ovroutski S, Peters B, Miera O, et al. Transcatheter creation of an aortopulmonary shunt in an animal model. Catheter Cardiovasc Interv 2010;75:563-569.

18. Kasper W, Meinertz T, Kersting F, Lollgen H, Just H. Wall motion characteristic of the right pulmonary artery in the suprasternal echocardiogram. J Clin Ultrasound 1980;8:201-206.

19. Green SE, Popp RL. The relationship of pulmonary valve motion to the motion of surrounding cardiac structures: a two-dimensional and dual m-mode echocardiographic study. Circulation 1981;64:107-112.

Source of support: Nil.

Conflict of interest: None declared. 